\title{
Significance of expression of glucagon-like peptide 1 receptor in pancreatic cancer
}

\author{
ANA INES CASES ${ }^{1}$, TAKAO OHTSUKA ${ }^{1}$, HIDEYO KIMURA $^{1}$, BIAO ZHENG $^{1}$, KOJI SHINDO $^{2}$, YOSHINAO ODA $^{2}$, \\ KAZUHIRO MIZUMOTO $^{1}$, MASAFUMI NAKAMURA ${ }^{1}$ and MASAO TANAKA ${ }^{1}$ \\ ${ }^{1}$ Department of Surgery and Oncology, Graduate School of Medical Sciences, Kyushu University, Higashi-ku, \\ Fukuoka 812-8582; ${ }^{2}$ Department of Anatomic Pathology, Graduate School of Medical Sciences, \\ Kyushu University, Higashi-ku, Fukuoka 812-8582, Japan
}

Received May 12, 2015; Accepted June 29, 2015

DOI: $10.3892 / o r .2015 .4138$

\begin{abstract}
Glucagon-like peptide 1 (GLP-1) induces insulin secretion and proliferation of pancreatic $\beta$-cells, and inhibits their apoptosis through the GLP-1 receptor (GLP-1R), thus providing a foundation for using GLP-1-based therapies for the treatment of type 2 diabetes. However, doubts have emerged regarding the drug safety of these therapies. We investigated the potential role of GLP-1R in pancreatic ductal adenocarcinoma (PDAC). GLP-1R expression was semi-quantitatively evaluated by immunohistochemistry in 48 PDAC samples, and its correlations with clinicopathological features were investigated. CFPAC-1 cells were used for GLP-1R knockdown to evaluate its effects on cell proliferation, migration and invasion. GLP-1R expression was positive in 23 tumors and negative in 25 tumors. No correlations were found between GLP-1R expression status and clinicopathological characteristics. Furthermore, GLP-1R expression status did not affect the patient prognosis $(\mathrm{P}=0.74)$. The majority of lymph node metastases (11 of 15 samples examined; $73 \%$ ) were positive for GLP-1R expression. Immunoreactivity for GLP-1R was also noted in sites of perineural and lymphovascular invasion. GLP-1R knockdown significantly reduced the proliferation, migration and invasion of CFPAC-1 cells $(\mathrm{P}<0.05)$. In conclusion, although GLP-1R is not an independent prognostic factor in PDAC patients, it appears to have some implications for PDAC metastatic ability.
\end{abstract}

\section{Introduction}

Pancreatic ductal adenocarcinoma (PDAC) is an aggressive disease that frequently presents in an advanced stage with

Correspondence to: Dr Takao Ohtsuka, Department of Surgery and Oncology, Graduate School of Medical Sciences, Kyushu University, 3-1-1 Maidashi, Higashi-ku, Fukuoka 812-8582, Japan

E-mail: takao-o@surg1.med.kyushu-u.ac.jp

Key words: GLP-1R, pancreatic cancer, metastasis distant metastases due to a late diagnosis. Furthermore, few advances have been achieved in terms of therapeutic strategies for PDAC, thus patient survival remains at very low levels (4\% at 5 years after diagnosis) (1). For these reasons, it is essential to make progress in understanding the biological behavior of the disease, in parallel with making headway in its diagnosis and therapeutic strategies.

G-protein-coupled receptors (GPCRs) comprise an extensive family of cell-surface receptors involved in several cellular actions, and are the targets of approximately half of the medications available nowadays $(2,3)$. Glucagon-like peptide 1 (GLP-1) receptor (GLP-1R), a member of the GPCR family, is involved in the so-called GLP-1-based therapies for the treatment of type 2 diabetes mellitus. It has been reported that treatment with the GLP-1R agonist exendin-4 did not affect the proliferation or survival of human pancreatic cancer cell lines (4), while other authors reported that treatment with the GLP-1R agonist liraglutide had an antitumorigenic effect on human pancreatic cancer cells in vitro and in vivo $(5,6)$. Regardless of these studies, continuing controversies have arisen that associate GLP-1-based therapies with high risks for the development of pancreatitis and pancreatic malignancies (7-14).

GLP-1R is a regulatory peptide receptor, and regulatory peptide receptors can be expressed in diverse human cancers (15), and thus are considered useful for diagnostic imaging (due to the high receptor density in tumor tissues) and for radiation therapy when possible; both notable and promising clinical strategies.

We recently discussed the possible relationship between GLP-1R and the malignant behavior of pancreatic neuroendocrine tumors (PNETs), and the use of GLP-1R for the diagnosis of these tumors, as well as in therapeutic strategies for hormonal syndrome and in advanced cases with metastases (16). Despite studies concerning the effects of GLP-1 agonists on pancreatic cancer cells (4-6), to our knowledge, there is no information regarding the activity of GLP-1R itself in pancreatic cancer cells. The aims of the present study were to assess GLP-1R expression in primary and metastatic sites of PDAC by immunohistochemical analysis and to examine whether GLP-1R knockdown affected pancreatic cancer cell function. 


\section{Materials and methods}

Pancreatic tissues and immunohistochemical staining. The study was approved by the Ethics Committee of Kyushu University (Fukuoka, Japan) and was conducted according to the Ethical Guidelines for Human Genome/Gene Research enacted by the Japanese Government and the Helsinki Declaration. Tissue samples of pancreatic cancer were obtained from 48 patients who underwent surgery for PDAC at Kyushu University Hospital between 2000 and 2009. Paraffin-embedded sections from the tissue samples were deparaffinized in xylene and rehydrated in a graded ethanol series. After endogenous peroxidase activity was blocked by incubation with $3 \%$ hydrogen peroxidase in methanol for $30 \mathrm{~min}$, antigen retrieval was achieved by microwaving the sections in citrate buffer for $20 \mathrm{~min}$, and the samples were then incubated overnight at $4^{\circ} \mathrm{C}$ with a mouse monoclonal anti-human GLP-1R antibody (clone 419208; dilution, 1:100; R\&D Systems, Minneapolis, MN, USA). For immunohistochemical labeling, we employed a peroxidase-labeled polymer $\left(\right.$ EnVision $^{\mathrm{TM}}+$ System-HRP Labeled Polymer Anti-Mouse; Dako, Carpinteria, CA, USA) and used 3,3'-diaminobenzidine tetrahydrochloride (Sigma-Aldrich, St. Louis, MO, USA) as a chromogen. Finally, the sections were counterstained with hematoxylin. Negative control staining without the primary antibody was performed to confirm the antibody specificity.

Evaluation of GLP-1R expression. There is general agreement that islets of Langerhans have a high density of GLP-1R (5,13,17-19). For this reason, and similar to a previous study (13), we used GLP-1R expression in these islets as an internal positive control for the immunohistochemical analysis. GLP-1R expression was evaluated as previously described $(16,20)$. Briefly, samples were analyzed using an intensity score (IS) that compared the levels of staining in tumor cells and islets of Langerhans (Fig. 1A and E) and graded them as follows: 0, no staining (Fig. 1A); 1, weak staining (Fig. 1B); 2, moderate staining (Fig. 1C); and 3, strong staining (Fig. 1D). A proportional score (PS) was also used to grade the samples as follows: 0 , staining in $<10 \%$ of the area; 1 , staining in $\geq 10 \%$ but $<30 \%$ of the area; 2 , staining in $\geq 30 \%$ but $<50 \%$ of the area; 3 , staining in $\geq 50 \%$ but $<80 \%$ of the area; and 4 , staining in $\geq 80 \%$ of the area. A final score (FS) rated the samples for GLP-1R expression as follows: GLP-1R-negative (FS 1), IS x PS = 0-3; and GLP-1R-positive (FS 2), IS x PS = 4-12. All samples were independently evaluated by two investigators (A.I.C. and K.S.) without knowledge of the records of each case.

Cell lines and culture conditions. The following 15 pancreatic cancer cell lines were used: AsPC-1, KP-2, KP-3, H48N and Panc-1 (generously provided by Dr H. Iguchi, National Shikoku Cancer Center, Matsuyama, Japan); HPC-3 (generously provided by Dr K. Yasoshima, Sapporo Medical University, Hokkaido, Japan); SUIT-2 and MIA PaCa-2 (Japanese Cancer Resource Bank, Tokyo, Japan); BxPC-3, Capan-1, Capan-2, CFPAC-1, Hs766T and SW 1990 (American Type Culture Collection (ATCC; Manassas, VA, USA); and NOR-P1 (21). In addition, we used a primary culture of normal human pancreatic epithelial cells (CS-PE cells;
Cell System-PE cells; Cell Systems; Applied Cell Biology Research Institute, Kirkland, WA, USA) and a human immortalized pancreatic ductal epithelial cell line (HPDE6-E6E7 clone 6; kindly provided by Dr Ming-Sound Tsao, University of Toronto, Toronto, Canada) (22). Most cells were cultured in Dulbecco's modified Eagle's medium (DMEM; SigmaAldrich) supplemented with streptomycin $(0.1 \mathrm{~g} / \mathrm{l})$, penicillin $(0.15 \mathrm{~g} / \mathrm{l}), \mathrm{NaHCO}_{3}(3.7 \mathrm{~g} / \mathrm{l})$ and $10 \%$ fetal bovine serum (FBS; Gibco $^{\circledR}$, Life Technologies, Grand Island, NY, USA). For Capan-1 cells, Iscove's modified Dulbecco's medium (IMDM; Gibco $^{\circledR}$ ) supplemented with $20 \%$ FBS was used. CS-PE cells were cultured in CSC Complete Recombinant Medium (Cell Systems Corporation, Kirkland, WA, USA), and HPDE cells were cultured in HuMedia-KG2 medium (Kurabo, Osaka, Japan). All the cells were kept in a humidified atmosphere of $10 \% \mathrm{CO}_{2} / 90 \%$ air at $37^{\circ} \mathrm{C}$.

Quantitative real-time reverse transcription-polymerase chain reaction. Total RNA was extracted from cultured cells using a High Pure RNA Isolation kit and DNase I (both from Roche Diagnostics, Mannheim, Germany) according to the manufacturer's instructions. RNA was quantified by its absorbance at $260 \mathrm{~nm}$ and evaluated for its purity by the $260 / 280$ absorbance ratio using a NanoDrop 1000 Spectrophotometer (Thermo Scientific, Waltham, MA, USA). Quantitative realtime reverse transcription-polymerase chain reaction (qRT-PCR) was performed using a QuantiTect SYBR-Green RT-PCR kit (Qiagen, Venlo, The Netherlands) and a CFX96 Touch $^{\text {TM }}$ Real-Time PCR Detection System (Bio-Rad Laboratories, Hercules, CA, USA). Briefly, each reaction mixture was initially incubated for $30 \mathrm{~min}$ at $50^{\circ} \mathrm{C}$ to allow RT. The PCR initial activation step was performed at $95^{\circ} \mathrm{C}$ for $15 \mathrm{~min}$ to activate the polymerase, followed by 40 three-step cycles of $15 \mathrm{~min}$ at $94^{\circ} \mathrm{C}, 30 \mathrm{~min}$ at $55^{\circ} \mathrm{C}$ and $30 \mathrm{~min}$ at $72^{\circ} \mathrm{C}$. The primers (Sigma-Aldrich) used were: GLP-1R forward, 5'-tctgcatcgtggtatccaaa-3' and GLP-1R reverse, 5'-cttggcaagtctgcatttga-3'; $18 \mathrm{~S}$ forward, 5'-gtaaccegttgaaccccatt-3' and $18 \mathrm{~S}$ reverse, 5'-ccatccaatcggtagtagccg-3'. Data were calculated as the relative GLP-1R expression levels normalized by the $18 \mathrm{~S}$ rRNA levels. All samples were run in duplicate or triplicate at least three times.

Western blot analysis. Cells were lysed in PRO-PREP ${ }^{\mathrm{TM}}$ (iNtRON Biotechnology, Seongnam, Korea). Cell lysate proteins $(5-15 \mu \mathrm{g})$ were fractionated in $4-15 \%$ sodium dodecyl sulfate-polyacrylamide gel electrophoresis gels (Bio-Rad Laboratories) and transferred to polyvinylidene difluoride membranes (Trans-Blot ${ }^{\circledR}$ Turbo $^{\mathrm{TM}}$; Bio-Rad Laboratories). The membranes were incubated overnight at $4^{\circ} \mathrm{C}$ with anti-GLP-1R (ab39072; dilution, $1 \mu \mathrm{g} / \mathrm{ml}$; Abcam, Cambridge, UK) or anti- $\beta$-actin (sc-81178; dilution, 1:2,500) antibodies, and then probed with secondary antibodies conjugated with horseradish peroxidase (both from Santa Cruz Biotechnology, Santa Cruz, CA, USA). Immunoreactive bands were analyzed using an ECL detection system (GE Healthcare, Buckinghamshire, UK) and chemiluminescence was detected using a ChemiDoc ${ }^{\mathrm{TM}}$ XRS (Bio-Rad Laboratories).

GLP-1R silencing by small interfering RNAs. For receptor silencing, we used the following small interfering RNAs 

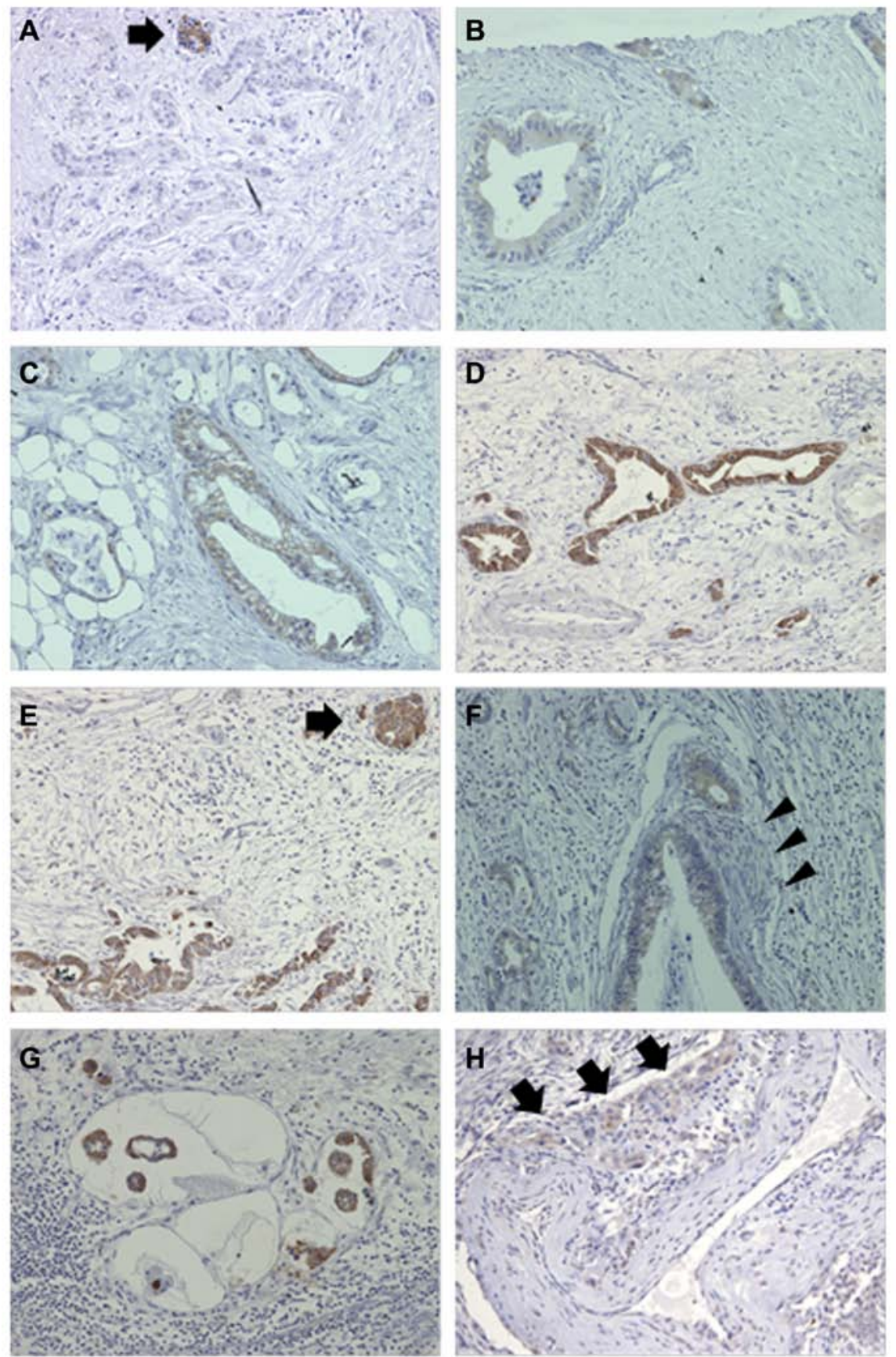

Figure 1. Immunohistochemical assessment of GLP-1R expression in pancreatic ductal adenocarcinoma. (A and E) Islets of Langerhans (arrow) were used as an internal positive control adjacent to tumor cells with (A) negative and (E) strong staining of GLP-1R. (A-D) Representative micrographs of immunohistochemical staining in PDAC specimens showing (A) negative, (B) weak, (C) moderate and (D) strong GLP-1R staining. (F-H) GLP-1R-positive tumor cells are also found in sites of perineural invasion (F, arrowheads indicate a nerve), lymphatic vessel invasion $(\mathrm{G})$ and vascular invasion (H, arrows indicate arterial wall invasion). Original magnifications, x100 in D and H; x200 in A, B, C, E, F and G. GLP-1R, glucagon-like peptide 1 (GLP-1) receptor; PDAC, pancreatic ductal adenocarcinoma.

(siRNAs; all purchased from Qiagen): GLP-1R 4 sense, 5'-gga acuccaacaugaacuatt-3' and GLP-1R 4 antisense, 5'-uaguucaugu uggaguucctg-3'; GLP-1R 5 sense, 5'-ggcucguucgugaauguc att-3' and GLP-1R 5 antisense, 5'-ugacauucacgaacgagctg-3'. A negative control siRNA (siControl; Qiagen) was used to verify the knockdown specificity. Transfections of CFPAC-1 cells (up to passage 8) were performed by electroporation using a Nucleofector ${ }^{\mathrm{TM}}$ device (Lonza, Cologne, Germany) in triplicate. Cells $\left(1.7-2 \times 10^{6}\right)$ were centrifuged at 2,000 x $\mathrm{g}$ for $1 \mathrm{~min}$, and the supernatant was discarded. Next, the cells were suspended in $95 \mu \mathrm{l}$ of Cell Line Nucleofector ${ }^{\mathrm{TM}}$ Solution V (Lonza), and $5 \mu \mathrm{l}$ of $20 \mu \mathrm{M}$ GLP-1R siRNA (siGLP-1R 4 or siGLP-1R 5) or siControl was added. The transfected cells were resuspended in DMEM 10\% FBS and cultured for $48 \mathrm{~h}$ before subsequent experiments. Silencing by siRNA was confirmed by qRT-PCR and western blot analysis.

Cell proliferation assay. Cell proliferation was evaluated by measuring the fluorescence intensity of propidium iodide (PI) as previously described (23). Transfected CFPAC-1 cells 
were suspended in DMEM without phenol red supplemented with $10 \%$ FBS, and seeded at a density of $2 \times 10^{4}$ cells/well in 24-well cell culture plates (BD Falcon, BD Biosciences, Franklin Lakes, NJ, USA). After $24 \mathrm{~h}$ of culture, the medium was changed to fresh serum-free medium for $24 \mathrm{~h}$ of culture under serum starvation. The following day, the medium was replaced with DMEM without phenol red supplemented with $1 \%$ FBS, and evaluated for cell proliferation by the PI assay. Briefly, PI $(30 \mu \mathrm{M})$ and digitonin $(600 \mu \mathrm{M})$ were added to each well and the fluorescence intensity was measured using a multimode microplate reader (Infinite F200; Tecan, Grödig, Austria) with 535-nm excitation and 620-nm emission filters. A separate well with the same medium but no cells was used to obtain a baseline PI signal as a control, and the difference between each sample well and the control well was evaluated. Cell proliferation was defined relative to the cell number measured at the beginning of the experiment (day 0). All experiments were performed in triplicate wells and repeated at least three times.

Invasion and migration assays. Invasion of transfected CFPAC-1 cells was assessed by counting the numbers of cells that invaded through Matrigel-coated Transwell chambers with $8-\mu \mathrm{m}$ pore size membranes (BD Biosciences). The Transwell inserts were coated with $20 \mu \mathrm{g} /$ well BD Matrigel ${ }^{\mathrm{TM}}$ (BD Biosciences). Each group of transfected cells $\left(1 \times 10^{5}\right)$ was suspended in $250 \mathrm{ml}$ of DMEM containing $1 \%$ FBS and placed in the upper chamber. The upper chamber was then placed in the well of a 24-well culture dish containing $750 \mathrm{ml}$ of DMEM with $10 \%$ FBS. In addition, cellular migration was assessed using uncoated Transwell inserts. After $24 \mathrm{~h}$ of incubation, the invading and migrating cells were fixed with $70 \%$ ethanol and stained with hematoxylin and eosin (H\&E). The cell numbers were counted under a light microscope in five random fields at a magnification of $\times 200$ for migration, and in one random field at a magnification of x 100 for invasion. The results were expressed as the mean numbers of counted cells/field. Each experiment was carried out in quadruplicate wells and repeated three times.

Statistical analysis. Statistical analyses were carried out using JMP 10 for Windows software (SAS Institute, Inc., Cary, NC, USA). Survival was evaluated from the time of surgery, with death as the end point. The cumulative survival rate was determined by Kaplan-Meier analysis. In cellular experiments, data are expressed as means $\pm \mathrm{SD}$. Differences between two groups were estimated by the Student's t-test or the $\chi^{2}$ test. Experiments were repeated at least three times. Differences were considered significant for values of $\mathrm{P}<0.05$.

\section{Results}

Evaluation of GLP- $1 R$ in pancreatic cancer. Immunohistochemical evaluation of GLP-1R was performed in 48 PDAC specimens from 48 patients, comprising 22 women and 26 men with a median age of 64 years (range, $36-82$ years) (Table I). The results revealed 23 tumors (48\%) with positive-GLP-1R expression and 25 tumors (52\%) with negative-GLP-1R expression (Table I). A noteworthy element was the presence of GLP-1R-positive tumor cells in invasive
Table I. Clinicopathological characteristics of the patients with pancreatic ductal adenocarcinoma and evaluation of GLP-1R expression $(n=48)$.

\begin{tabular}{|c|c|}
\hline Characteristics & Data \\
\hline Age, median (range), years & $64(36-82)$ \\
\hline \multicolumn{2}{|l|}{ Gender } \\
\hline Female & $22(46)$ \\
\hline Male & $26(54)$ \\
\hline \multicolumn{2}{|l|}{ pT category } \\
\hline pT1 & $1(2)$ \\
\hline pT2 & $1(2)$ \\
\hline pT3 & $43(90)$ \\
\hline pT4 & $3(6)$ \\
\hline \multicolumn{2}{|l|}{ pN category } \\
\hline pN0 & $6(12)$ \\
\hline pN1 & $42(88)$ \\
\hline \multicolumn{2}{|l|}{ UICC stage } \\
\hline I & $1(2)$ \\
\hline II & $42(88)$ \\
\hline III & $3(6)$ \\
\hline IV & $2(4)$ \\
\hline \multicolumn{2}{|l|}{ Histological grade } \\
\hline G1 & $8(17)$ \\
\hline $\mathrm{G} 2$ & $16(33)$ \\
\hline G3 & $24(50)$ \\
\hline \multicolumn{2}{|l|}{ Lymphatic invasion } \\
\hline Negative & $8(17)$ \\
\hline Positive & $40(83)$ \\
\hline \multicolumn{2}{|l|}{ Vascular invasion } \\
\hline Negative & $8(17)$ \\
\hline Positive & $40(83)$ \\
\hline \multicolumn{2}{|l|}{ Neural invasion } \\
\hline Negative & $5(10)$ \\
\hline Positive & $43(90)$ \\
\hline \multicolumn{2}{|l|}{ Surgical margin } \\
\hline Negative & $29(60)$ \\
\hline Positive & $19(40)$ \\
\hline \multicolumn{2}{|l|}{ GLP-1R expression } \\
\hline Negative & $25(52)$ \\
\hline Positive & $23(48)$ \\
\hline
\end{tabular}

Data are presented as $\mathrm{n}(\%)$. UICC, Union for International Cancer Control; GLP-1R, glucagon-like peptide 1 (GLP-1) receptor.

localization areas, such as perineural invasion, lymph vessel invasion and vascular invasion (Fig. 1F-H).

GLP-1R expression and its correlations with clinicopathological features and the survival analysis. Table II shows the associations between GLP-1R expression and the clinicopathological features of the 48 patients. There were no significant 
Table II. Relationships between GLP-1R expression and clinicopathological features $(n=48)$.

\begin{tabular}{|c|c|c|c|}
\hline Characteristics & $\begin{array}{c}\text { GLP-1R } \\
\text { positive } \\
(n=23)\end{array}$ & $\begin{array}{c}\text { GLP-1R } \\
\text { negative } \\
(n=25)\end{array}$ & P-value \\
\hline Age, years & & & 0.77 \\
\hline$\geq 65$ & $11(46)$ & $13(54)$ & \\
\hline$<65$ & $12(50)$ & $12(50)$ & \\
\hline Gender & & & 0.15 \\
\hline Female & $13(59)$ & $9(41)$ & \\
\hline Male & $10(38)$ & $16(62)$ & \\
\hline pT category & & & 0.95 \\
\hline $\mathrm{pT} 1 / \mathrm{pT} 2$ & $1(50)$ & $1(50)$ & \\
\hline $\mathrm{pT} 3 / \mathrm{pT} 4$ & $22(48)$ & $24(52)$ & \\
\hline pN category & & & 0.44 \\
\hline pN0 & $2(33)$ & $4(67)$ & \\
\hline pN1 & $21(50)$ & $21(50)$ & \\
\hline UICC stage & & & 0.45 \\
\hline I & 1 & 0 & \\
\hline II & $20(48)$ & $22(52)$ & \\
\hline III/IV & $2(40)$ & $3(60)$ & \\
\hline Histological grade & & & 0.77 \\
\hline $\mathrm{G} 1 / \mathrm{G} 2$ & $12(50)$ & $12(50)$ & \\
\hline G3 & $11(46)$ & $13(54)$ & \\
\hline Lymphatic invasion & & & 0.36 \\
\hline Negative & $5(63)$ & $3(37)$ & \\
\hline Positive & $18(45)$ & $22(55)$ & \\
\hline Vascular invasion & & & 0.52 \\
\hline Negative & $3(37)$ & $5(63)$ & \\
\hline Positive & $20(50)$ & $20(50)$ & \\
\hline Neural invasion & & & 0.71 \\
\hline Negative & $2(40)$ & $3(60)$ & \\
\hline Positive & $21(49)$ & $22(51)$ & \\
\hline Surgical margin & & & 0.51 \\
\hline Negative & $15(52)$ & $14(48)$ & \\
\hline Positive & $8(42)$ & $11(58)$ & \\
\hline
\end{tabular}

Data are presented as n (\%). UICC, Union for International Cancer Control; GLP-1R, glucagon-like peptide 1 (GLP-1) receptor.

associations between the receptor expression status and the clinicopathological features. Similarly, the overall survival rates showed no significant difference between the positive and negative groups for GLP-1R expression ( $\mathrm{P}=0.74$; Fig. 2).

GLP-1R analysis in metastatic sites. From the total of 42 patients with lymph node metastasis (Table I), 15 metastatic lymph node samples were randomly selected and immunohistochemically evaluated for the expression of GLP-1R. Most of the samples (11 of $15 ; 73 \%$ ) showed positive staining for GLP-1R (Table III, Fig. 3A), while the remaining four samples

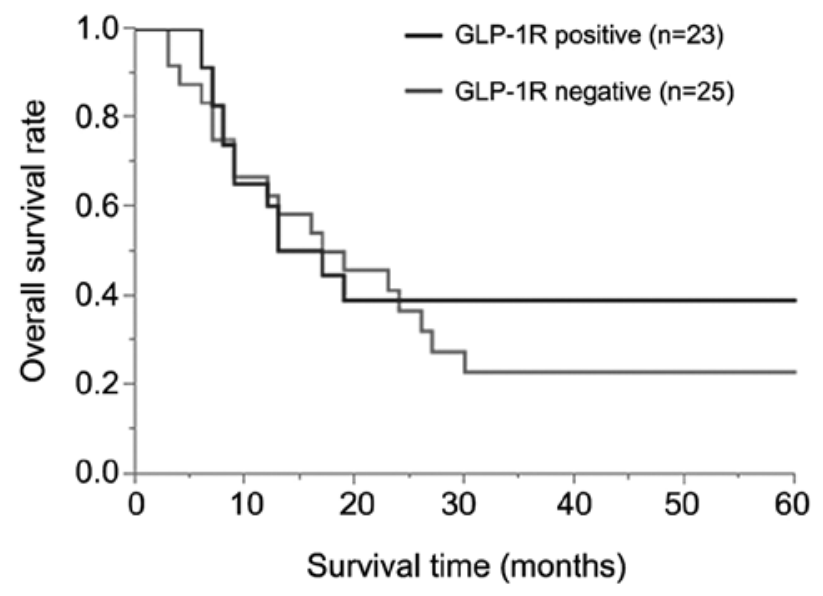

Figure 2. Overall survival curves of pancreatic ductal adenocarcinoma patients after resection according to the immunohistochemical assessment of GLP-1R. No difference in the survival rates is observed between the positive and negative groups for GLP-1R expression $(\mathrm{P}=0.74)$. GLP-1R, glucagon-like peptide 1 (GLP-1) receptor.

(27\%) were classified as GLP-1R-negative (Table III, Fig. 3B). Although there was a correlation between GLP-1R expression in the primary site and the metastatic site in 13 samples (i.e. positive-positive or negative-negative), two samples with negative expression in the primary sites showed positive-GLP-1R expression in the metastatic sites.

GLP-1R knockdown has a positive impact on the malignant behavior of CFPAC-1 pancreatic cancer cells. First, we investigated the presence of GLP-1R expression in several pancreatic cancer cell lines as well as in normal pancreatic cells by qRT-PCR and western blot analysis (Fig. 4A). Next, for knockdown experiments, the cell line CFPAC-1 was selected due to its high receptor expression at both the mRNA and protein levels. Knockdown efficacy was verified by qRT-PCR and western blot analysis at $48 \mathrm{~h}$ post-transfection (Fig. 4B). We found that GLP-1R knockdown significantly decreased the proliferation of CFPAC- 1 cells after 4 days of culture when using siGLP-1R 4, and after 5 days of culture when using both siGLP-1R 4 and siGLP-1R 5, as compared with siControl (Fig. 4C). Similarly, the receptor knockdown significantly decreased the cell migration and invasion compared with siControl (Fig. 4D).

\section{Discussion}

We analyzed the expression of GLP-1R in 48 surgically resected PDAC specimens, and examined its relationships with several clinicopathological factors. The immunohistochemical analysis procedure was the same as that used in our previous study (16), in which we examined GLP-1R expression in PNETs and found no significant associations between the receptor expression status and several clinicopathological characteristics. Similar to our previous study, GLP-1R expression was not found to be a predictive factor for survival in PDAC patients. The receptor expression showed dissimilar levels (at both the mRNA and protein levels) even among pancreatic cancer cells, indicating that the receptor expression was markedly variable 
Table III. Immunohistochemical evaluation of GLP-1R in metastatic sites: analysis of 15 metastatic lymph node samples.

\begin{tabular}{cccccc}
\hline $\begin{array}{l}\text { Patient } \\
\text { no. }\end{array}$ & $\begin{array}{c}\text { Age } \\
\text { (years) }\end{array}$ & Gender & $\begin{array}{c}\text { Degree of } \\
\text { differentiation }\end{array}$ & $\begin{array}{c}\text { GLP-1R expression in } \\
\text { primary site }\end{array}$ & $\begin{array}{c}\text { GLP-1R expression in } \\
\text { lymph node sample }\end{array}$ \\
\hline 1 & 61 & F & G3 & Positive & Positive \\
2 & 79 & F & G3 & Positive & Positive \\
3 & 66 & M & G3 & Positive & Positive \\
4 & 63 & F & G1 & Negative & Positive \\
5 & 55 & M & G3 & Positive & Positive \\
6 & 67 & F & G3 & Positive & Positive \\
7 & 61 & M & G3 & Negative & Negative \\
8 & 65 & M & G3 & Negative & Positive \\
9 & 59 & M & G3 & Positive & Positive \\
10 & 73 & M & G2 & Positive & Positive \\
11 & 60 & F & G3 & Positive & Negative \\
12 & 50 & F & G2 & Negative & Negative \\
13 & 73 & M & G2 & Negative & Positive \\
14 & 55 & F & G3 & Positive & Negative \\
15 & 60 & M & G3 & Negative & \\
\hline
\end{tabular}

F, female; M, male; GLP-1R, glucagon-like peptide 1 (GLP-1) receptor.
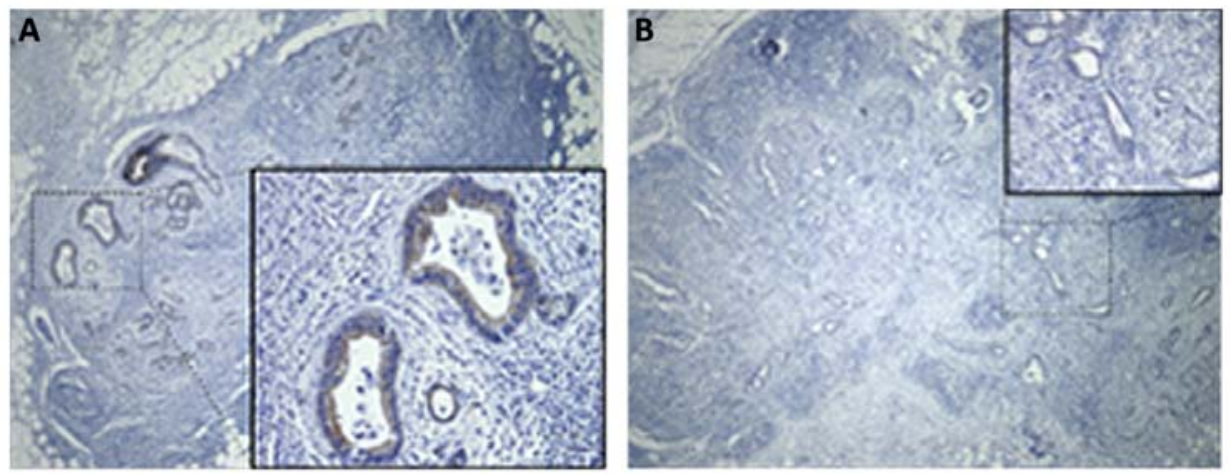

Figure 3. Immunohistochemical assessment of GLP-1R in metastatic sites. (A and B) Illustrative photomicrographs of immunohistochemical staining in metastatic lymph nodes for a GLP-1R-positive case (A, original magnification, x40; inset x200) and a GLP-1R-negative case (B, original magnification, x40; inset $\mathrm{x} 100)$. GLP-1R, glucagon-like peptide 1 (GLP-1) receptor.

from one cell to another (heterogeneity), and that even if there was a relationship between GLP-1R and tumor behavior, this was lost when the samples were evaluated together.

We evaluated samples of metastatic lymph nodes, and found that most of these samples were GLP-1R-positive (11 of 15 samples; 73\%). It was interesting that 13 samples showed a direct correlation for GLP-1R expression between the primary site and its metastatic counterpart, while the remaining two samples with negative GLP-1R expression in the primary site showed positive GLP-1R expression in the metastatic site, suggesting that cells expressing GLP-1R may have an increased metastatic ability. In other words, even though the expression status in the primary site was judged to be negative, there could be a minor compartment of GLP-1R-positive cells arising through tumor heterogeneity, and these cells may be able to metastasize to lymph nodes. To our knowledge, this is the first study to reveal the expression of GLP-1R in metastatic samples of PDAC, a finding to consider given the negative impact that metastases have on patient survival. Additional investigations of GLP-1R expression in other metastatic sites, such as the liver and lung are warranted.

Although a previous study described an immunohistochemical analysis of GLP-1R in PDAC and its relationships with several clinicopathological factors (5), the present study involved a larger number of patients for immunohistochemical evaluation of the receptor, and included samples from metastatic sites. In the previous study, Zhao et al (5) found that negative GLP-1R expression in PDAC samples was associated with a larger tumor diameter (this information was additionally presented by the same authors in a second study) (6), conjointly with lymphatic metastasis and a poorer overall survival compared with patients with GLP-1R-positive tumors. We think that the differences compared with our findings exceed the mere facts of using antibodies from different 


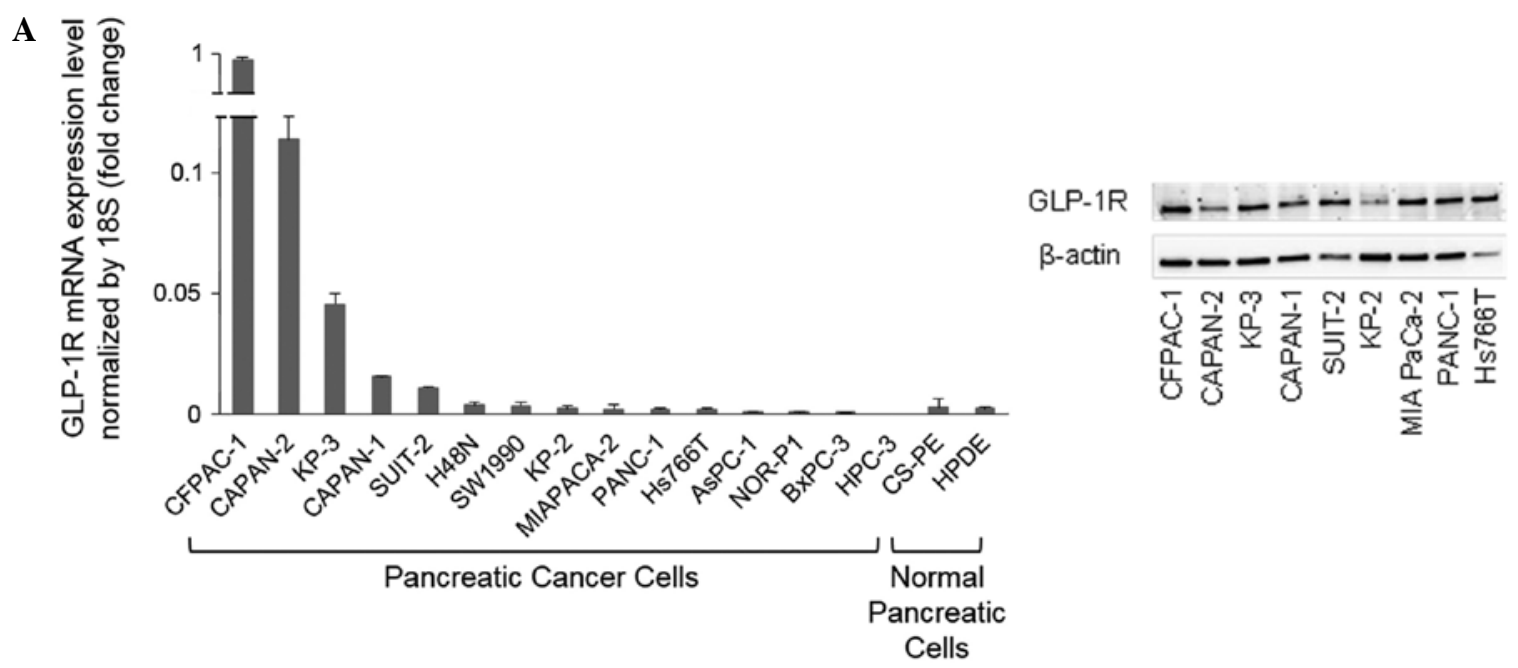

B

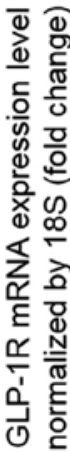

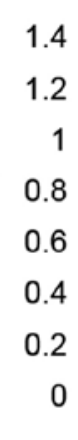

C

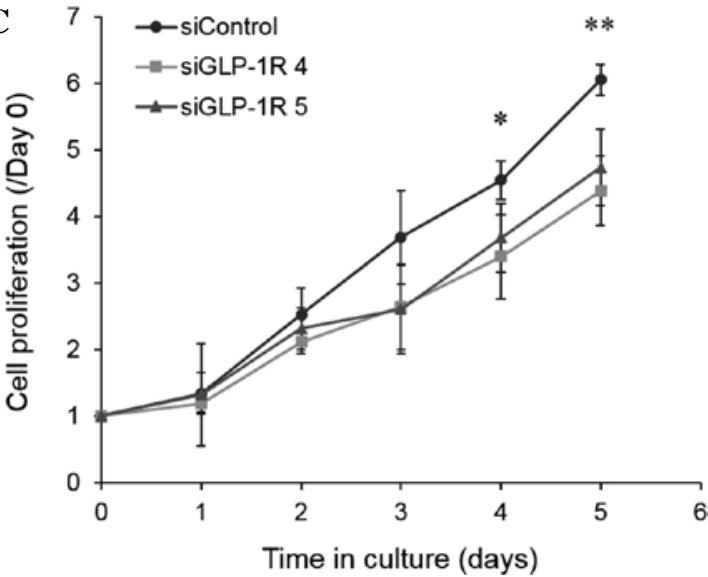

D
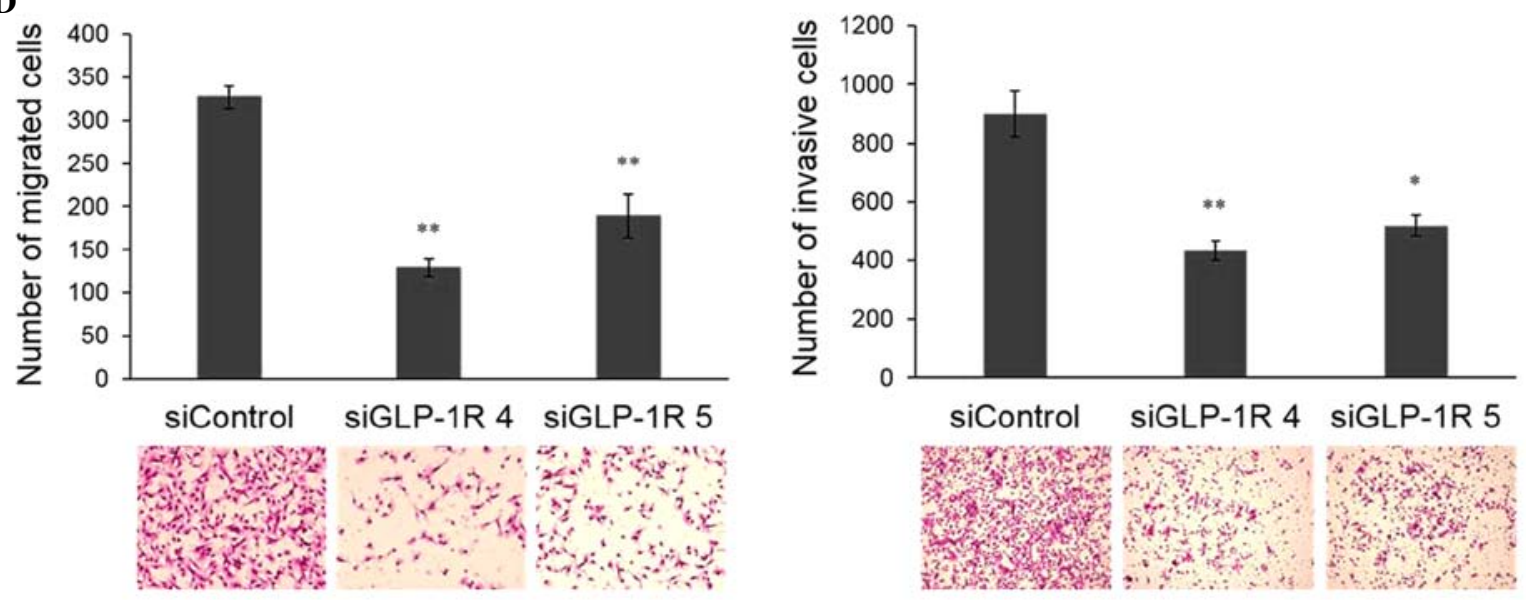

Figure 4. Presence of GLP-1R in cell lines and effects of its knockdown. (A) qRT-PCR was carried out to examine the presence of GLP-1R in several pancreatic cancer cell lines and normal pancreatic cells. (B) For additional western blot analysis, we selected cells with high expression at the mRNA level (CFPAC-1, CAPAN-2 and KP-3), and some cells with low expression (CAPAN-1, SUIT-2, KP-2, MIA PaCa-2, PANC-1 and Hs766T). We then chose the CFPAC-1 cell line for further experiments due to its high expression of GLP-1R at both the mRNA and protein levels. GLP-1R knockdown was achieved in CFPAC-1 cells using two different siRNAs, sigLP-1R 4 and siGLP-1R 5. Both siGLP-1R 4 and siGLP-1R 5 effectively reduced the receptor expression at the mRNA and protein levels in CFPAC-1 cells, as compared with siControl. (C) The cells were seeded at $48 \mathrm{~h}$ post-transfection, and cell proliferation was measured at the indicated time points using a propidium iodide assay. GLP-1R knockdown significantly decreased the cell proliferation. ${ }^{*} \mathrm{P}<0.05$, siGLP-1R 4 vs. siControl; ${ }^{* *} \mathrm{P}<0.05$, siGLP-1R 4 and siGLP-1R 5 vs. siControl. (D) Knockdown of GLP-1R expression significantly reduced the migration and invasion abilities of CFPAC-1 cells. ${ }^{*} \mathrm{P}=0.0001 ;{ }^{* *} \mathrm{P}<0.0001$. Representative photomicrographs of migrated cells $(\mathrm{H} \& \mathrm{E}$, original magnification, $\mathrm{x} 200)$ and invasive cells $(\mathrm{H} \& \mathrm{E}$, original magnification, x100) are shown. GLP-1R, glucagon-like peptide 1 (GLP-1) receptor; H\&E, hematoxylin and eosin.

commercial brands or different sample numbers and could possibly arise through methodological differences in the immunohistochemical evaluations.
As we observed GLP-1R-positive tumor cells in invasive areas as well as in metastatic lymph nodes, we questioned whether the receptor influences the metastatic ability of 
pancreatic cancer cells. To address this question, we performed siRNA experiments to achieve receptor knockdown, and found that GLP-1R knockdown decreased the proliferation of CFPAC-1 cells, and also induced noticeable decreases in the cell migration and invasion abilities. To the best of our knowledge, this is the first study to disclose that GLP-1R silencing decreases the malignant behavior of PDAC cells, and these results may support our immunohistochemical findings, wherein metastatic lymph nodes were frequently GLP-1R-positive. Taken together, the data obtained in the present study suggest that GLP-1R plays a role in the metastatic potential of PDAC cells.

In the absence of any treatment, we hypothesized that GLP-1R may be functioning without a ligand to mediate its activation; for example, through autophosphorylation with the consequent triggering of cellular signals. Alterations in GPCRs have been described and linked to carcinogenesis $(3,24)$, and thus GLP-1R may not be an exception. Notably, at the beginning of the experiments using CFPAC-1 cells with GLP-1R knockdown, a dose of 10\% FBS in the medium was used, yet the results were not significant. Subsequently, we decided to reduce the FBS concentration to $1 \%$, resulting in significant differences under this condition. In view of this situation, and since the sequences of the GLP-1 peptide are quite similar among mammals (25), our hypothesis was that traces of bovine GLP-1 in the FBS could be stimulating some GLP-1Rs still present in the cell membrane, thereby interfering with the results. Using western blot analysis and ELISA, we searched for the presence of bovine GLP-1 in the FBS, but the results were negative (data not shown). Nevertheless, we cannot totally confirm the absence of GLP-1 in the FBS, or the possible presence of another metabolite that functions as a receptor agonist. In our previous study (16), we reported that GLP-1 treatment increased the proliferation as well as the migration of the insulinoma cell line MIN6, and numerous studies have associated GLP-1-based therapies with pancreatic disease in recent years $(7-14,17)$. Moreover, using mutant GLP-1Rs, Ge et al (26) described that even with a mutation of the putative signal sequence, ligand binding to the mutant receptor was observed with conserved cAMP production. In summary, although an aberrant GLP-1R presented an agonist-independent functionality as the siRNA data suggest, an agonist-dependent functionality cannot be discarded. One limitation of the present study is that the downstream signals related to GLP-1R knockdown were not investigated. However, the in vitro data firmly demonstrated that GLP-1R silencing decreased the malignant ability of PDAC cells. Further experiments will be necessary to clarify the cell signals involved in this hypothetical ligand-independent receptor process.

In our previous study (16), we discussed the potential use of GLP-1R for the diagnosis and treatment of metastatic PNETs. In a similar way, we can also think of GLP-1R as a molecular target not only for the treatment of PDAC, but also as a diagnostic molecular marker for metastatic PDAC, e.g., its utilization in scintigraphy techniques. However, given the results described in the present study, wherein GLP-1R promoted the metastatic potential of PDAC cells, it is useful to mention that GLP-1R showed an excellent response to radiolabeled antagonist binding (19). The latter observation posits that the hypothetical use of a radiolabeled antagonist for the diagnosis of advanced PDAC would not involve undesired side-effects, unlike the case for many agonists. Although GLP-1R showed minimal antagonist-induced internalization compared with agonists (27), receptor internalization is considered to be a very attractive feature in terms of retention of radioactivity for radionuclide therapy application (28).

In conclusion, although GLP-1R expression was not found to be an independent prognostic factor in PDAC patients by immunohistochemical analysis, it appears to have some implications for PDAC metastatic ability. It is necessary to monitor the long-term safety of GLP-1 mimetic therapies, as well as to examine GLP-1R as a possible molecular target for the diagnosis and treatment of advanced PDACs.

\section{Acknowledgements}

The authors thank Ms. Emiko Manabe and Ms. Miyuki Omori (Pancreatic Cancer Laboratory, Department of Surgery and Oncology, Kyushu University) for their technical assistance. The present study was supported by JSPS KAKENHI grant nos. 24390318, 24390319, 25293285, 25670582 and 26293305. A.I.C. is supported by a doctoral fellowship provided by the Ministry of Education, Culture, Sports, Science and Technology of Japan. B.Z. is supported by a doctoral fellowship provided by the China Scholarship Council. K.S. is supported by a postdoctoral fellowship provided by the Japan Society for the Promotion of Science.

\section{References}

1. Vincent A, Herman J, Schulick R, Hruban RH and Goggins M: Pancreatic cancer. Lancet 378: 607-620, 2011

2. Pierce KL, Premont RT and Lefkowitz RJ: Seven-transmembrane receptors. Nat Rev Mol Cell Biol 3: 639-650, 2002.

3. Dorsam RT and Gutkind JS: G-protein-coupled receptors and cancer. Nat Rev Cancer 7: 79-94, 2007.

4. Koehler JA and Drucker DJ: Activation of glucagon-like peptide-1 receptor signaling does not modify the growth or apoptosis of human pancreatic cancer cells. Diabetes 55: 1369-1379, 2006.

5. Zhao H, Wang L, Wei R, Xiu D, Tao M, Ke J, Liu Y, Yang J and Hong T: Activation of glucagon-like peptide-1 receptor inhibits tumourigenicity and metastasis of human pancreatic cancer cells via PI3K/Akt pathway. Diabetes Obes Metab 16: 850-860, 2014.

6. Zhao H, Wei R, Wang L, Tian Q, Tao M, Ke J, Liu Y, Hou W, Zhang L, Yang J, et al: Activation of glucagon-like peptide-1 receptor inhibits growth and promotes apoptosis of human pancreatic cancer cells in a cAMP-dependent manner. Am J Physiol Endocrinol Metab 306: E1431-E1441, 2014.

7. Ayoub WA, Kumar AA, Naguib HS and Taylor HC: Exenatideinduced acute pancreatitis. Endocr Pract 16: 80-83, 2010.

8. Lee PH, Stockton MD and Franks AS: Acute pancreatitis associated with liraglutide. Ann Pharmacother 45: e22, 2011.

9. Iyer SN, Drake AJ III, West RL, Mendez CE and Tanenberg RJ: Case report of acute necrotizing pancreatitis associated with combination treatment of sitagliptin and exenatide. Endocr Pract 18: e10-e13, 2012.

10. Elashoff M, Matveyenko AV, Gier B, Elashoff R and Butler PC: Pancreatitis, pancreatic, and thyroid cancer with glucagon-like peptide-1-based therapies. Gastroenterology 141: 150-156, 2011.

11. Singh S, Chang HY, Richards TM, Weiner JP, Clark JM and Segal JB: Glucagonlike peptide 1-based therapies and risk of hospitalization for acute pancreatitis in type 2 diabetes mellitus: A population-based matched case-control study. JAMA Intern Med 173: 534-539, 2013.

12. Matveyenko AV, Dry S, Cox HI, Moshtaghian A, Gurlo T, Galasso R, Butler AE and Butler PC: Beneficial endocrine but adverse exocrine effects of sitagliptin in the human islet amyloid polypeptide transgenic rat model of type 2 diabetes: Interactions with metformin. Diabetes 58: 1604-1615, 2009. 
13. Gier B, Matveyenko AV, Kirakossian D, Dawson D, Dry SM and Butler PC: Chronic GLP-1 receptor activation by exendin-4 induces expansion of pancreatic duct glands in rats and accelerates formation of dysplastic lesions and chronic pancreatitis in the $\mathrm{Kras}^{\mathrm{G} 12 \mathrm{D}}$ mouse model. Diabetes 61: 1250-1262, 2012.

14. Butler AE, Campbell-Thompson M, Gurlo T, Dawson DW, Atkinson M and Butler PC: Marked expansion of exocrine and endocrine pancreas with incretin therapy in humans with increased exocrine pancreas dysplasia and the potential for glucagonproducing neuroendocrine tumors. Diabetes 62: 2595-2604, 2013.

15. Reubi JC: Peptide receptors as molecular targets for cancer diagnosis and therapy. Endocr Rev 24: 389-427, 2003.

16. Cases AI, Ohtsuka T, Fujino M, Ideno N, Kozono S, Zhao M, Ohuchida K, Aishima S, Nomura M, Oda Y, et al: Expression of glucagon-like peptide 1 receptor and its effects on biologic behavior in pancreatic neuroendocrine tumors. Pancreas 43: 1-6, 2014.

17. Nakamura T, Ito T, Uchida M, Hijioka M, Igarashi H, Oono T, Kato M, Nakamura K, Suzuki K, Jensen RT, et al: PSCs and GLP-1R: Occurrence in normal pancreas, acute/chronic pancreatitis and effect of their activation by a GLP-1R agonist. Lab Invest 94: 63-78, 2014.

18. Hörsch D, Göke R, Eissele R, Michel B and Göke B: Reciprocal cellular distribution of glucagon-like peptide-1 (GLP-1) immunoreactivity and GLP-1 receptor mRNA in pancreatic islets of rat. Pancreas 14: 290-294, 1997.

19. Waser B and Reubi JC: Radiolabelled GLP-1 receptor antagonist binds to GLP-1 receptor-expressing human tissues. Eur J Nucl Med Mol Imaging 41: 1166-1171, 2014.

20. Furukawa T, Kuboki Y, Tanji E, Yoshida S, Hatori T, Yamamoto M, Shibata N, Shimizu K, Kamatani N and Shiratori K: Whole-exome sequencing uncovers frequent GNAS mutations in intraductal papillary mucinous neoplasms of the pancreas. Sci Rep 1: 161, 2011.
21. Sato N, Mizumoto K, Beppu K, Maehara N, Kusumoto M, Nabae T, Morisaki T, Katano M and Tanaka M: Establishment of a new human pancreatic cancer cell line, NOR-P1, with high angiogenic activity and metastatic potential. Cancer Lett 155: $153-161,2000$.

22. Furukawa T, Duguid WP, Rosenberg L, Viallet J, Galloway DA and Tsao MS: Long-term culture and immortalization of epithelial cells from normal adult human pancreatic ducts transfected by the E6E7 gene of human papilloma virus 16. Am J Pathol 148: $1763-1770,1996$.

23. Zhang L, Mizumoto K, Sato N, Ogawa T, Kusumoto M, Niiyama H and Tanaka M: Quantitative determination of apoptotic death in cultured human pancreatic cancer cells by propidium iodide and digitonin. Cancer Lett 142: 129-137, 1999.

24. Allen LF, Lefkowitz RJ, Caron MG and Cotecchia S: G-proteincoupled receptor genes as protooncogenes: Constitutively activating mutation of the alpha $1 \mathrm{~B}$-adrenergic receptor enhances mitogenesis and tumorigenicity. Proc Natl Acad Sci USA 88: $11354-11358,1991$.

25. Knudsen LB, Hastrup S, Underwood CR, Wulff BS and Fleckner J: Functional importance of GLP-1 receptor species and expression levels in cell lines. Regul Pept 175: 21-29, 2012.

26. Ge Y, Yang D, Dai A, Zhou C, Zhu Y and Wang MW: The putative signal peptide of glucagon-like peptide-1 receptor is not required for receptor synthesis but promotes receptor expression. Biosci Rep 34: e00152, 2014.

27. Brom M, Joosten L, Oyen WJ, Gotthardt M and Boerman OC: Radiolabelled GLP-1 analogues for in vivo targeting of insulinomas. Contrast Media Mol Imaging 7: 160-166, 2012.

28. Bodei L, Paganelli G and Mariani G: Receptor radionuclide therapy of tumors: A road from basic research to clinical applications. J Nucl Med 47: 375-377, 2006. 